\title{
Investigation of Distress of a Reinforced Earth Wall in Hong Kong
}

- Dr. Dominic OK Lo, BSc(Eng), MSC, PhD, MHKIE, RPE(G)

- Chief Geotechnical Engineer at Geotechnical Engineering Office, Civil Engineering and Development Department, HKSAR Government, Hong Kong (corresponding author dominiclo@cedd.gov.hk)

- Jane Cunningham, M.Eng, MIAust.

- Principal Engineer, Fugro (Hong Kong) Limited, Hong Kong

- Prof. John B Burland, CBE, DSc(Eng), FREng, FRS, NAE

- Emeritus Professor, Imperial College London, UK

- ORCID number 0000-0002-2337-6487

\section{Full contact details of corresponding author:}

Dr. LO O Kwan, Dominic

Ch Geo Engr / Landslip Preventive Measures 1

1/F, Civil Engineering and Development Building, 101 Princess Margaret Rd, Homantin, Kowloon, Hong Kong

dominiclo@cedd.gov.hk

Tel: +85227605811

\section{Abstract}

During an intense rainstorm on 22 May 2013, severe distress occurred at a reinforced earth wall in Hong Kong. The wall was under construction and nearing completion at the time of the incident. The distress involved dislodgement of 78 facing panels, a total soil loss of about 1,300 $\mathrm{m}^{3}$ and a disturbed groundmass of some $5,500 \mathrm{~m}^{3}$. The distress occurred at three localised areas along the wall, with the formation of a sinkhole within the backfilled soil mass, referred to as the backyard of the wall. The incident resulted in significant soil deposition within the surface drainage system, flooding and debris overspill onto the road carriageway below and it caused havoc to the local community. Subsequent to the incident, a detailed investigation was conducted to establish the probable causes and mechanism of the incident. This paper highlights some salient points of the investigation, the key findings and the lessons learnt from the incident.

Keywords: Retaining wall, failure, reinforced earth, geotechnical engineering 


\section{INTRODUCTION}

2 In the early morning of 22 May 2013, severe distress involving dislodgement of facing panels and

3 loss of soil occurred at a reinforced earth wall (Wall R22) at a construction site for a site formation

4 project, above Shun On Road, Sau Mau Ping in Hong Kong (Figure 1). Wall R22 was under

5 construction at the time of the incident. The incident involved a $1,300 \mathrm{~m}^{3}$ loss of soil and a

6 distressed groundmass of 5,500 $\mathrm{m}^{3}$ (Figure 2). The majority of washout debris was deposited

7 over the hillside and within a drainage culvert in front of the Wall with some debris overspilling the

8 culvert onto Shun On Road. The incident resulted in temporary closure of a section of Shun On

9 Road for 18 days. No casualty was reported as a result of the incident. Subsequent to the incident, a detailed investigation was carried out to establish the probable causes and mechanism of the incident. The investigation included interviewing eye-witnesses, field inspections, ground investigation and review of related design and construction records of the project (FSWJV, 2013).

\section{SITE DESCRIPTION}

Wall R22 is located below a formed platform (Platform C1) at the western part of the 20 ha project site (Figure 1). It is situated over a westerly to southerly sloping terrain, in the vicinity of two drainage lines buried by the site formation works (Figure 3).

Wall R22 is a $300 \mathrm{~m}$ long reinforced earth wall with a curved alignment on plan, sub-divided longitudinally from Bay $1 \mathrm{a}$ to Bay $22 \mathrm{~b}$ (Figure 3 ) with varying retained heights to accommodate the topographic profile of the site. Upon its completion, it would have a maximum height of $36.5 \mathrm{~m}$, comprising four tiers, namely the top tier, upper tier, middle tier and lower tier (Figure 4). Each tier is set back from the lower one, forming a $2 \mathrm{~m}$ wide berm and opening (hereafter known as 'tier opening'). At the time of the incident, the top tier of the wall was under construction, with the top surface of the compacted fill (referred to as 'backyard') at about +146 mPD corresponding to a maximum retained height of around $21 \mathrm{~m}$ over the affected wall sections.

Adjoining the northern end of Wall R22 is another reinforced earth wall (Wall R26). A staircase 
of Wall R26 and the northern end of Wall R22 (Figure 3). The cascade feeds via a streamcourse into a culvert underneath Shun On Road for discharge (Figure 3).

\section{DESCRIPTION OF THE INCIDENT}

The distress of the wall was confined to the area between Bay 4 and Bay 9 of Wall R22, from the middle tier up to the top tier. It generally comprised three localized areas of distress at the interfaces between Bays 4 and 5, between Bays 6 and 7 and between Bays 8 and 9 as shown in Figures 2 and 5 to 7.

The localized distress at the interface between Bays 4 and 5 involved the dislodgement of 40 panels at the middle and upper tiers, with approximately $510 \mathrm{~m}^{3}$ of soil loss behind the dislodged panels and their adjoining panels (Figure 7). The extent of soil loss appeared to be confined within $2 \mathrm{~m}$ behind the panels. There was no sign of dislodgement or observable displacement of the top tier panels.

The localized distress at the interface between Bays 6 and 7 involved the dislodgement of 38 panels from the middle to the top tiers (Figure 7). Approximately $340 \mathrm{~m}^{3}$ of soil loss was observed immediately behind the dislodged panels and their adjacent panels. Loss of soil was mainly limited to within $2 \mathrm{~m}$ behind the panels. At the backyard of the wall, a sinkhole measuring approximately $8 \mathrm{~m}$ wide by $12.5 \mathrm{~m}$ long on plan, extending up to $9 \mathrm{~m}$ deep and with an approximate volume of $450 \mathrm{~m}^{3}$ was observed. Figure 8 shows the cross-sections pre- and post-incident at the interface between Bays 6 and 7. The central part of the soil loss appeared to extend a long way back from the face of the wall and would have likely connected to the sinkhole as shown (Figure 8).

The dislodged panels either fell backwards into the reinforced fill body or hung by the reinforcement straps attached to the panels. None of the dislodged panels fell off from the wall.

The localized distress at the interface between Bays 8 and 9 involved a relatively small scale of soil loss (approximately $5 \mathrm{~m}^{3}$ ) immediately behind the panels at the top of the upper tier (Figures 2 and 7). Soil debris of around $5 \mathrm{~m}^{3}$ was deposited on the top of the middle tier below the location 
where loss of soil was noted. No signs of dislodgement or notable movement of panels was observed at the affected facing panels.

62

\section{INVESTIGATION OF THE INCIDENT}

A detailed investigation was launched immediately after the incident. Whilst the intense rainstorm was anticipated to be a key factor in the incident, the potential contribution of other factors such as the wall design, structural and drainage detailing, materials, construction quality and surrounding site activities were not immediately evident and had to be examined as part of the investigation process. The investigation comprised incident mapping, field reconnaissance of catchment area, eye-witness interviews, ground investigation and a desktop review of all related retaining wall, site formation and drainage designs and site records. Quick capture of the postincident conditions at and around the wall was critical owing to the immediate works required to stabilize Wall R22 and remediate the site drainage conditions as well as the ongoing construction site activity, all of which were continuously altering the post-incident setting. A field team of several personnel undertook mapping of the wall and surrounding areas with particular attention to the drainage conditions of the construction site and surrounding areas. Full time supervision of the urgent stabilisation works was also provided to progressively examine, sample and record the wall conditions and materials, including each of the recovered dislodged facing panels, as the distressed zone was cut back.

An unmanned aerial vehicle (UAV) was deployed to capture the details of the wall distress where safe access was not feasible as well as to provide large area image capture to produce a digital elevation model (DEM) of the surface runoff characteristics over a catchment area of some $106,000 \mathrm{~m}^{2}$. Post-incident ground investigation comprising GCO probes tests (a handheld lightweight dynamic probing test) and excavation of inspection pits was undertaken at various locations within and beyond the distressed area of the wall. The GCO probes identified loosening of the soil beneath the area of soil loss around the interface between Bays 8 and 9 .

As well as key records relating to the design and construction records of the wall, the desktop review identified that a previous minor (but similar) distress incident had also occurred earlier in 
the wall's construction in July 2012, the location of which was observed to be coincident with that of the failed Bay 4 and 5 zone of the May 2013 incident (see Section 6 below).

92

\section{WALL R22}

94

\subsection{Design of Wall R22}

\subsubsection{Structural Arrangement and Overall Stability of Wall R22}

According to the design, Wall R22 typically comprised mass concrete foundations supporting a reinforced fill body. The mass concrete foundations were configured in a stepped profile along the alignment of the wall (Figure 6). On top of the reinforced fill body, there would be an L-shaped reinforced concrete retaining wall (Figure 4).

100

The reinforced fill body was composed of an elemental system of concrete facing panels with a typical size of $1.6 \mathrm{~m}$ high by $2.5 \mathrm{~m}$ wide. Each concrete facing panel was tied back by rows of metal reinforcement straps ranging from $4.6 \mathrm{~m}$ to $19.5 \mathrm{~m}$ in length. Behind the panels were compacted fill materials which provided anchorage for the reinforcement straps to support the concrete facing panels. The lowermost tier of the concrete facing panels were generally founded on the mass concrete foundations whilst the panels of the tiers above were generally founded on the compacted fill materials with $300 \mathrm{~mm}$ wide by $150 \mathrm{~mm}$ high strip peg footings. Socket joints were provided to interlock the panels to adjacent panels. Geotextile was placed behind the panel joints to prevent soil loss. Some of the concrete facing panels were secured to the front face of the mass concrete foundations (referred to as 'dummy panels'), with a $300 \mathrm{~mm}$ wide separation with concrete infill.

113 The wall was designed as a tiered structure, with a $2 \mathrm{~m}$ wide tier opening created at the top of the

114 lower, middle and upper tiers (Figure 4). The soil near the top surface of the tier opening was under a low overburden pressure in comparison to the surcharge created at the base of the tier above and it was assumed in the design that this soil was not subject to any build-up of high water pressure. There was no provision in the design to guard against any soil loss through the tier openings. At the time of the incident, a thin layer of gravel was placed on the top of the tier opening for planting purpose. 
121 Wall stability checking was undertaken on a bay-by-bay approach at a critical section of each bay.

122 External stability checking included sliding, overturning, bearing and loss of overall slope stability modes of failure whilst internal stability checking included tensile failure of reinforcement, pull out

124 of reinforcement, sliding along reinforcement, sliding on soil planes between reinforcement and wedge failure. In both external and internal designs, it was assumed that groundwater would be intercepted by drainage layers surrounding the wall and along the temporary cut surface with no flow or build-up of water pressure within the reinforced fill body. For the checking of external stability, a design groundwater pressure equivalent to one-third of the retained height was assumed to act on the reinforced fill wall.

\subsubsection{Drainage Arrangement of Wall R22}

132 The drainage arrangement of the wall typically comprised two drainage layers at the back of the wall: a vertical one directly behind the reinforced fill body and an inclined one resting on the surface of the temporary cut as shown in Figure 4 . The inclined drainage layer at the back of the wall was designed to extend up to two-thirds of the retained height of the reinforced fill body. A layer of geotextile was provided as a filter at the interfaces of the inclined and vertical drainage layers with adjacent ground. There was also a base drainage layer overlying the mass concrete foundations at the base of the recompacted fill body. All three drainage layers were connected (Figures 4 and 10).

At the steps of the mass concrete foundations, the adjacent base drainage layers were connected

142 to each other by vertical drainage layers which are referred to in the paper as 'vertical connecting drainage layers' (Figure 10). All the drainage layers were prescribed as $500 \mathrm{~mm}$ thick, comprising granular materials and are much more permeable than the compacted fill materials.

The drainage design arrangement of the wall resulted in the 'vertical connecting drainage layers' at the interfaces between Bays 4 and 5, between Bays 6 and 7, and between Bays 8 and 9 being in close proximity to a tier opening (see Figure 10). Over the portion of the reinforced earth wall under construction, such arrangement was unique at these three wall locations, which were 
observed to be coincident with the location of the three localised distressed zones. The implication of this drainage layer arrangement is further discussed in Section 7.

152

153 Water collected in the vertical and inclined drainage layers at the back of the reinforced fill body

154 was intended to flow along the base drainage layer and vertical connecting drainage layers within 155 Wall R22 until it reached one of 4 outlet points along the $300 \mathrm{~m}$ long wall. At either end of the wall 156 (over Bay 1 and Bay 21/22), the base drainage layer directly discharged to $250 \mathrm{~mm}$ diameter toe drain located beneath a footpath in front of the wall whilst at Bay 9 and at Bay 15 respectively, $150 \mathrm{~mm}$ and $225 \mathrm{~mm}$ diameter subsoil drain pipes were prescribed to divert the water from the base drainage layer to the toe drain. Additionally, a row of weepholes $(100 \mathrm{~mm}$ diameter at $2.5 \mathrm{~m}$ horizontal spacing) were prescribed at the concrete facing panels along the base drainage layer at Bay 5, Bay 6, Bays 12 to 14 and Bays $18 \mathrm{a}$ to $19 \mathrm{~b}$.

162

Following an incident on 24 July 2012 (see Section 6), additional $100 \mathrm{~mm}$ diameter weepholes at the joints of dummy panels were prescribed at Bays 5 and 6 and an additional $250 \mathrm{~mm}$ diameter half-perforated subsoil drain pipe embedded sub-horizontally at the 'vertical connecting drainage layer' at the interface between Bays 4 and 5 was prescribed. This outlet pipe was fed by three sub-vertical $250 \mathrm{~mm}$ diameter half-perforated subsoil drain pipes installed at the back of Bays 2 to 6 . Underneath the $250 \mathrm{~mm}$ diameter subsoil drain outlet pipe was a layer of $600 \mathrm{~mm}$ thick compacted soil fill.

The provisions of the drainage arrangement of the wall appeared to be on a prescriptive basis. No assessment was found to show the adequacy of the drainage arrangement of the wall or the possible impacts of a large amount of surface water ingress to the wall through the drainage 174 layers.

The investigation identified that the thickness of the drainage layers was found to be variable. Photographic records show the drainage layers at some locations at the rear of the wall were thicker than $500 \mathrm{~mm}$ whilst localised exposure of the base drainage layer above the Bay 4 mass concrete foundation varied from $300 \mathrm{~mm}$ to $400 \mathrm{~mm}$ in thickness. Contamination of the drainage 
layers with finer soil particles was observed in the local exposures of the base drainage layers over Bays 4 to 6 and the 'vertical connecting drainage layer' at the interface between Bays 4 and 5.

\subsection{Construction of Wall R22}

The wall was generally constructed in accordance with the engineering design as mentioned above, except that the inclined and vertical drainage layers at the back of the wall were constructed as a single combined layer between Bay 3 and Bay 11 as shown in the pre-incident cross-section in Figure 8.

At the time of the incident, the construction of the reinforced fill portion of the wall between Bay 2 and Bay 16 was on-going. The top tier of the wall was under construction, with the top surface of the compacted fill at about +146 mPD. The top surface of the compacted fill was slightly graded away from the wall face. The backyard at Bays 4 to 7 of the wall was a topographical low point in the vicinity, as evidenced by water ponding observed on the day before the incident. No temporary surface drainage was provided at this location. The top end of the drainage layer at the back of Wall R22 was exposed in this area (Figures 8 and 9). This allowed any surface water that accumulated at the backyard to penetrate inside Wall R22.

198

\subsection{Monitoring of Wall R22}

200

A series of movement markers was erected at the top panel of each tier along the wall alignment with measurements taken since 19 July 2012 at typically fortnightly intervals. The maximum movement recorded over the affected bays prior to the incident was $20 \mathrm{~mm}$ vertical settlement at the upper tier of Bay 4 and $18 \mathrm{~mm}$ outward horizontal movement at the middle tier of Bay 7 . The recorded movements of the affected bays were all within the allowable tolerances. Based on available site records, seepage flows issuing from the wall face were noted since May 2012. Seepage was mainly observed between Bays 1 and 5 as well as Bay 9 of the wall. Both clear and muddy seepages had been noted with varying degrees of intensity. Most of the seepage was through the joints of the dummy panels (i.e. at a level at or below the base of the base drainage layer). Limited water seepage points were observed at Bays 6 and 7 . 
212 The construction of Wall R22 commenced in mid-2010. Prior to the 22 May 2013 incident, Wall 213 R22 suffered some panel dislodgement in 2012 (Figure 11). The rainfall was not particularly 214 intense, with a return period generally of two years or less for various durations considered. 215 Approximately $40 \mathrm{~m}^{3}$ of soil loss was apparent immediately behind the affected panels, in the 216 vicinity of the 'vertical connecting drainage layer' at the interface between Bays 4 and 5, as well 217 as in the backyard of the wall. At that time, the wall was formed up to a level of about $+135 \mathrm{mPD}$, 218 with the height of reinforced fill about $10 \mathrm{~m}$.

219

220 Site records showed that, at the time of the 24 July 2012 incident, there was no temporary drainage in the backyard of Bays 4 and 5 . Water ponding in this area was observed shortly after the incident suggesting that it was a local low point. Similar to the 22 May 2013 incident, the upper end of the combined vertical/inclined drainage layer in the backyard of Bays 4 and 5 was exposed. Such arrangement could allow significant ingress of surface water into Wall R22 during rainstorms.

226

227

It was probable that ingress of surface water via the exposed drainage layer at the back of the wall was a key contributory factor of the distress. Following the 24 July 2012 incident, the wall was partially removed from Bay 2 to Bay 6 in a stepped profile down to the level of the collapsed panel and then reconstructed with enhanced internal drainage measures.

231

\section{DIAGNOSIS OF THE 22 MAY 2013 INCIDENT}

At the time of the incident, the rainstorm was intense, with a 1-hour maximum rolling rainfall of $234135 \mathrm{~mm}$ which corresponded to a return period of more than 200 years. It was established that at the time of the incident, the site drainage provisions at formed platforms of the project site were not efficient in conveying surface runoff offsite, resulting in overflow of surface water towards Wall R22. This overflow, together with surface runoff collected at the backyard of Walls R22 and R26, were the primary sources of water reaching the wall on 22 May 2013. 
240 In addition, there was no temporary drainage provision at the backyard of Bays 4 to 7 to drain 241 away any surface runoff that would have accumulated at this local low point. The exposed 242 drainage layer at the back of the reinforced fill body remained unguarded against surface runoff 243 and allowed water ingress at times of rainfall over this area. This exposed drainage layer would 244 allow a large amount of water to percolate into the base drainage layers of Wall R22. The water ingress probably exceeded the flow capacity of the drainage outlets of Wall R22. As a result, high water pressures would have built up in the base drainage layers as well as in the 'vertical connecting drainage layers'.

248

249 Figure 10 is a three-dimensional depiction of the arrangement of the subsurface drainage layers and tiers between Bays 4 and 9 . It can be seen from the various sections shown in Figure 10 that the lowest tier openings are all located above the base drainage layers. In particular, at the sections coinciding with the vertical steps in the mass concrete foundations (denoted by an asterisk) the tier openings are almost coincident with the 'vertical connecting drainage layers'. The thickness of soil cover between the tier openings and the 'vertical connecting drainage layers' was very thin (see the sections at $\mathrm{B}, \mathrm{E}$ and $\mathrm{H}$ cut along the 'vertical connecting drainage layers' in Figure 10). These three locations were also coincident with the development of the three distress areas at the interfaces between Bays 4 and 5, between Bays 6 and 7 and between Bays 8 and 9 .

The overburden pressure exerted by the soil layers at the tier openings would have been very small. The build-up of high water pressures at the underlying drainage layer would have exceeded the overburden pressures resulting in hydraulic uplift of the soil layer and piping at the tier opening. Given the configuration of the wall, it is also possible that the soil in the vicinity of the tier openings was subject to high local stress ratio (shear/effective vertical stress) and was therefore susceptible to local failure under a build-up of high water pressure in the vicinity.

It is probable that the large cross-sectional area of the 'vertical connecting drainage layers' at a single location meant that much larger upward flows of water could take place above these layers than elsewhere above the base drainage layer. Therefore, once loss of soil was initiated, upward flow of water would concentrate at these locations along the tier causing erosion and continued 
soil loss. This would lead to the formation of voids in the compacted fill near the tier opening. Such a continuing erosion process would allow the upward migration of voids (ravelling) combined with

272 slumping of the compacted fill into the underlying voids. The phenomenon is supported by the void observed at the top of a tier (i.e. the upper tier) at Bays 8 and 9, together with soil debris deposited on the tier opening below (i.e. the middle tier). The post-incident ground investigation works involving GCO probes showed loosening of the soil beneath the void.

276

277 The ravelling process which involved slumping of the fill would induce tensile forces in the 278 reinforcement straps attached to the panels. When the induced tensile forces were large enough to shear off the socket connections at the panel joints, as well as to overcome any remaining earth pressure of the fill behind the panels, backwards panel dislodgement would occur. The observed damage on the panels at Bays 4 and 5 , and Bays 6 and 7 where the front part of the panel sockets had been sheared off whilst the rear part of the socket generally remained intact, supports this postulated onset mechanism of the panel dislodgement.

The distress would proceed with displacement or even dislodgement of the panels above due to loss of support by the supporting panels below, which could further promote soil loss. The postulated progression of the distress mechanism at the interface between Bays 4 and 5 is summarized in Figure 12 with each stage being numbered and described. The distress at the interface between Bays 6 and 7 appears to be more developed than that between Bays 4 and 5 , with the formation of a sinkhole at the back - see the post-incident cross-section in Figure 8. This sinkhole formation could have been due to a larger amount of water ingress into the wall or due to the presence of a subsoil drain pipe at the latter location which could help to reduce the volume of water issuing out of the top of the tier.

295 It is probable that the 24 July 2012 incident underwent the same distress mechanism as that of the 22 May 2013 incident. The site settings at the time are similar with the presence of a low point at the backyard of the wall, the presence of exposed end of drainage layer at the backyard, together with the distressed location occurring at the interface with the 'vertical connecting drainage layer' in close proximity to a tier opening. There is also the close correlation of the time 
of the incident with rainfall, as well as the similarity in the distress mode (i.e. backward dislodgement of panel with soil loss behind the panels and at the backyard). The smaller scale in distress observed in the 24 July 2012 incident would be due to the less intense rainfall at the time of the incident and hence lower volumes of water discharging through the tier opening.

304

305 A review of the design records indicates that the provisions of the drainage arrangement of the wall appeared to be on a prescriptive basis for a permanent condition where the drainage layer behind the reinforced fill body would be capped by compacted fill at the top. No assessment was made of the adequacy of the drainage provisions of the wall or the likely adverse impacts under excessive ingress of water into the wall, in particular during construction. The tiered structure of the wall was not designed to cater for build-up of high water pressure near the tier openings and there were no provisions to guard against soil loss in the tier opening.

313 Upon review of related design and construction records, there is no indication that the distress

314 was caused by any fault in the permanent design or workmanship of the permanent works of Wall 315 R22. However, the internal detailing involving a 'vertical connecting drainage layer' adjacent to 316 the step of mass concrete foundation, in the vicinity of a tier opening, is vulnerable to piping in the event of an unintended ingress of a significant amount of water. This is precisely what took place in this incident during an intense rainstorm while the wall was under construction.

319

\section{LESSONS LEARNT}

321 The key lessons learnt from the incident are as follows:

- Overwhelming of temporary drainage provisions during site formation works in severe rainfall events can lead to failure of reinforced fill structures and serious consequences. Due attention should be given during construction to ensuring adequate temporary drainage provisions and precautionary and mitigation measures to discharge the surface water and subsurface water safely.

- The integrity and stability of reinforced fill structures are vulnerable to excessive ingress of water and such structures require special attention in design and construction control. 
- The tiered wall arrangement, with tier openings in close proximity of internal drainage layers proved to be vulnerable in the event of unintended water ingress.

Subsequent to the incident, the following technical recommendations were promulgated by the Geotechnical Engineering Office (GEO, 2014):

- A risk assessment should be carried out for projects involving site formation which may

\section{CONCLUSIONS}

The 22 May 2013 incident at Wall R22 was piping-related and initiated during an intense rainstorm. The site surface drainage provisions at the filled platforms at the time of the incident 
of surface water during the intense rainfall, resulting in overflow of surface water towards Wall R22. The wall was under construction and the backyard at Bays 4 to 7 was a topographic low point. The temporary site drainage provisions were yet to be constructed at this location. The exposed drainage layer at the backyard of Wall R22 in this area was susceptible to ingress of surface water. Excessive water ingress through the exposed top end of the drainage layer behind the reinforced fill body probably generated high water pressure at and in the vicinity of the drainage layer near the wall face. The high water pressure would have initiated hydraulic uplift and piping at tier openings. The presence of the 'vertical connecting drainage layers' beneath resulted in a large amount of locally concentrated water flowing through and eroding the drainage and fill materials within the wall.

Surface water that reached and accumulated at the exposed drainage layer during the severe rainstorm was probably the principal source of water leading to the distress. The contribution of subsurface water was probably insignificant.

There is no indication that the distress was caused by any fault in the permanent design or workmanship of the permanent works of Wall R22. However, the internal detailing involving a 'vertical connecting drainage layer' adjacent to the step of mass concrete foundation, in the vicinity of a tier opening, is vulnerable to piping in the event of unintended ingress of a significant amount of water, which took place in this incident during an intense rainstorm while the wall was under construction.

This incident highlights that overwhelming of temporary drainage provisions during site formation works in severe rainstorms can lead to geotechnical failures and serious consequences. The integrity and stability of reinforced fill structures are vulnerable to excessive ingress of water and such structures require special attention in design and construction control.

The combined use of an UAV together with a large deployment of ground personnel was essential to gather the post-incident details to understand and examine the probable causes and mechanisms of the incident. The amalgamation of methods suited the gathering of information on 
the macro and micro scales. In particular, the use of UAV enabled the rapid gathering of both vantages and large area coverage that would otherwise be impossible to gain due to access and safety standpoints.

392

Acknowledgements

This paper is published with the permission of the Head of the Geotechnical Engineering Office and the Director of Civil Engineering and Development, Government of the Hong Kong Special Administrative Region.

397

398

References

Fugro Scott Wilson Joint Venture (2013) Report on the 22 May 2013 Distress at a Reinforced

400 Earth Wall at a Construction Site above Shun On Road, Sau Mau Ping. Fugro Scott Wilson Joint Venture, $86 \mathrm{p}$.

402

Geotechnical Engineering Office (2014) GEO Technical Guidance Note No.40 - Guidelines on Temporary Drainage Provisions and Precautionary Measures against Severe Rainfall during Site Formation Works and Construction of Reinforced Fill Structures. Geotechnical Engineering Office, Hong Kong, 4 p.

406

\section{Figure captions}

408 Figure 1. Key plan for the site formation project

409 Figure 2. Overall view of 22 May 2013 incident at Wall R22

410 Figure 3. Layout plan of Wall R22

411 Figure 4. Typical cross-section of Wall R22

412 Figure 5. Plan of the 22 May 2013 incident at Wall R22

413 Figure 6. Elevation of the 22 May 2013 incident at Wall R22

414 Figure 7. Aerial views of the 22 May 2013 incident at Wall R22

415 Figure 8. Pre- and post-incident cross-sections of Wall R22 at the interface between Bays 6 and $416 \quad 7$

417 Figure 9. Backyard of Wall R22 on 21 May 2013

418 Figure 10.3D spatial arrangement of the drainage layers and tiers

419 Figure 11. View of July 2012 incident at Bay 4/5

420 Figure 12. Sequence of distress at Bays $4 / 5$ of Wall R22

421 


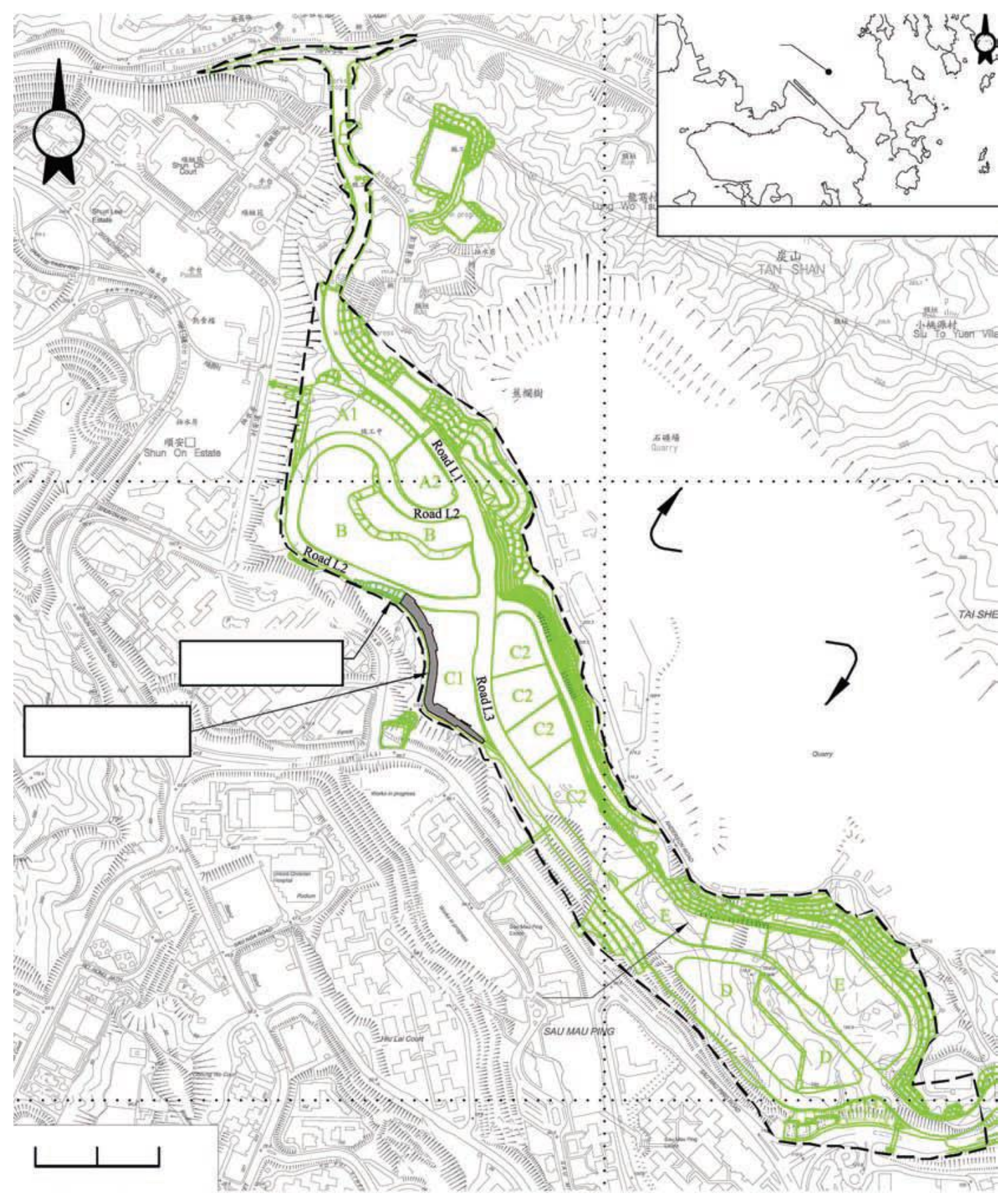

Figure 1. Key plan for the site formation project 
435

436

437

438

439

440

441

442

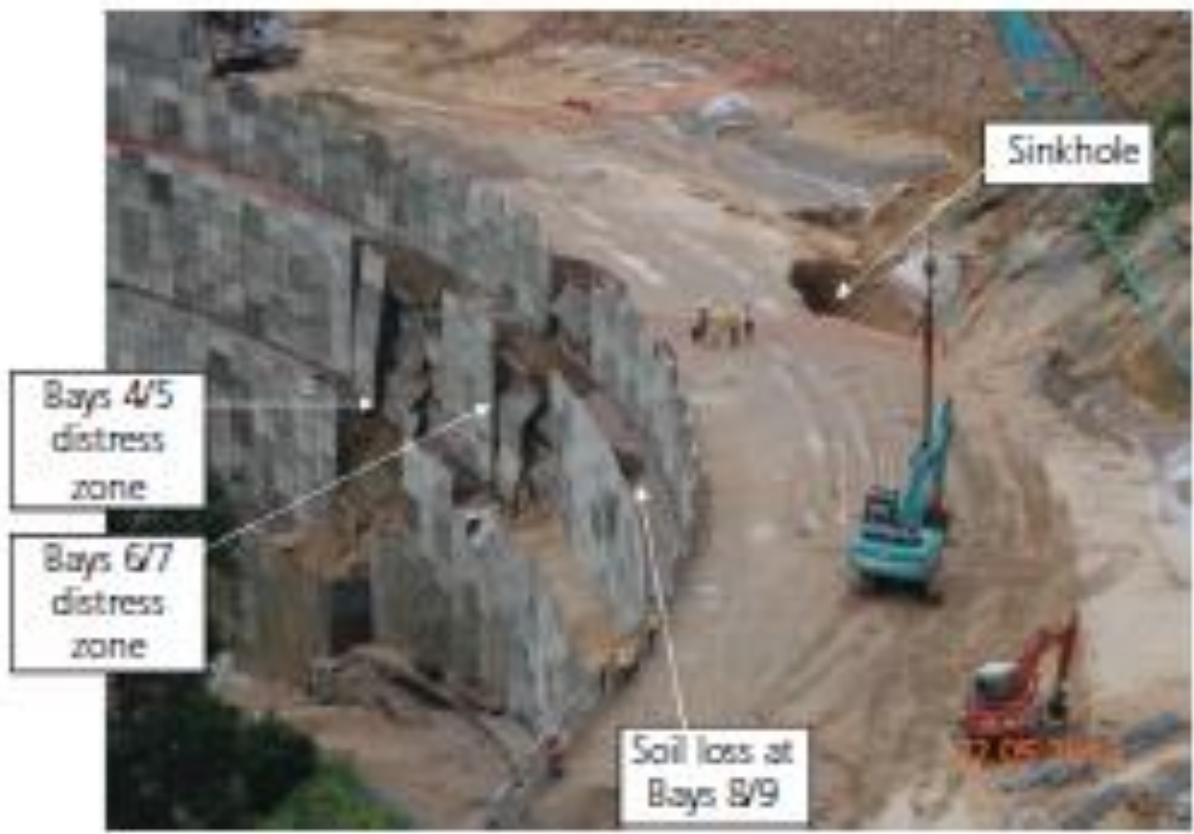

443

444

445

446

Figure 2. Overall view of 22 May 2013 incident at Wall R22

447

448

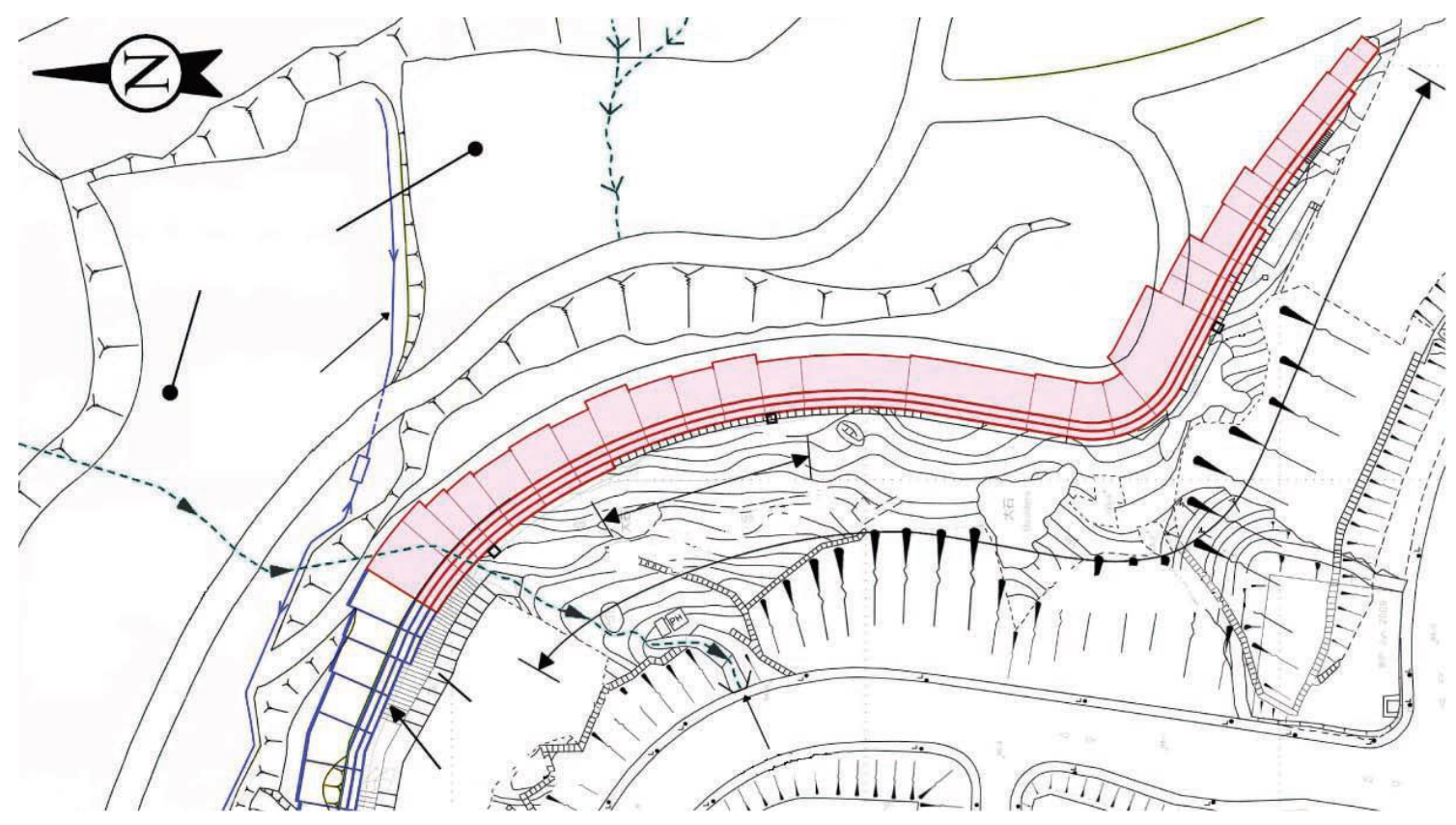

450

451

Figure 3. Layout plan of Wall R22

452 


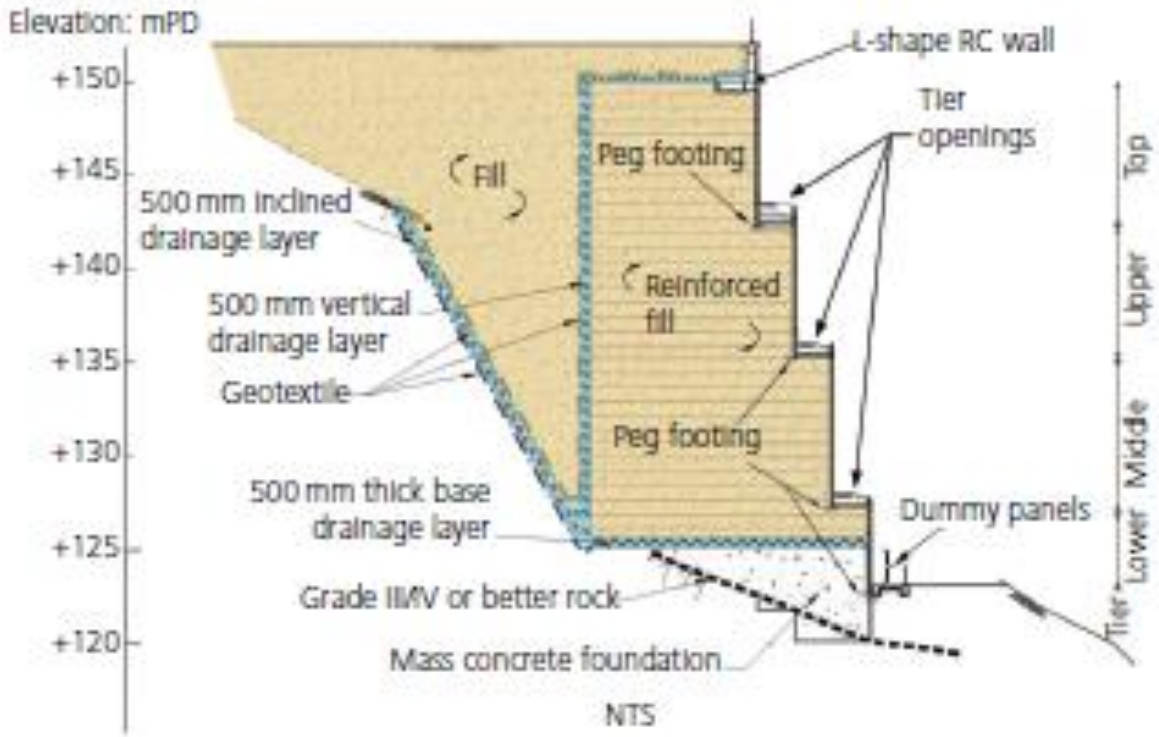

467

468

469

Figure 4. Typical cross-section of Wall R22

470

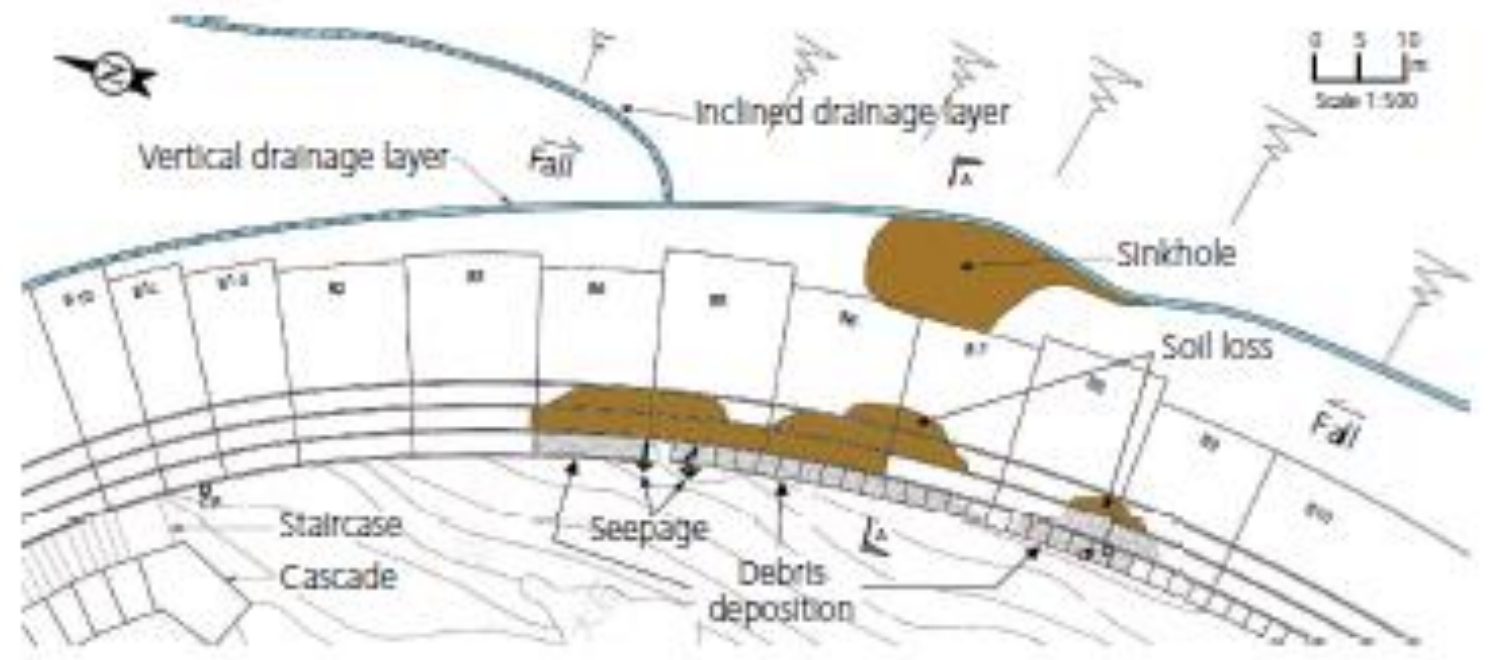

471

472

473

474

Figure 5. Plan of the 22 May 2013 incident at Wall R22

475 
476

477

478

479

480

481

482

483

484

485

486

487

488

489

490

491

492

493

494

495

496

497

498

499

500

501

502

503

504

505

506

507

508

509

510

511

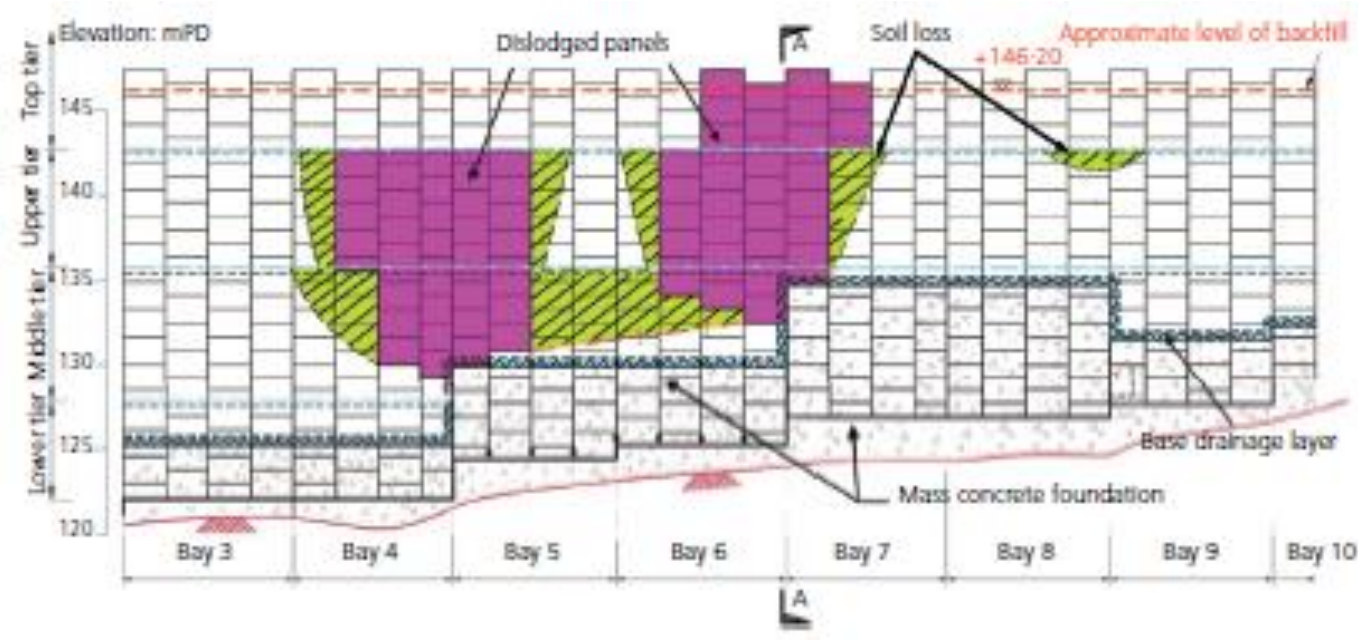

Figure 6. Elevation of the 22 May 2013 incident at Wall R22
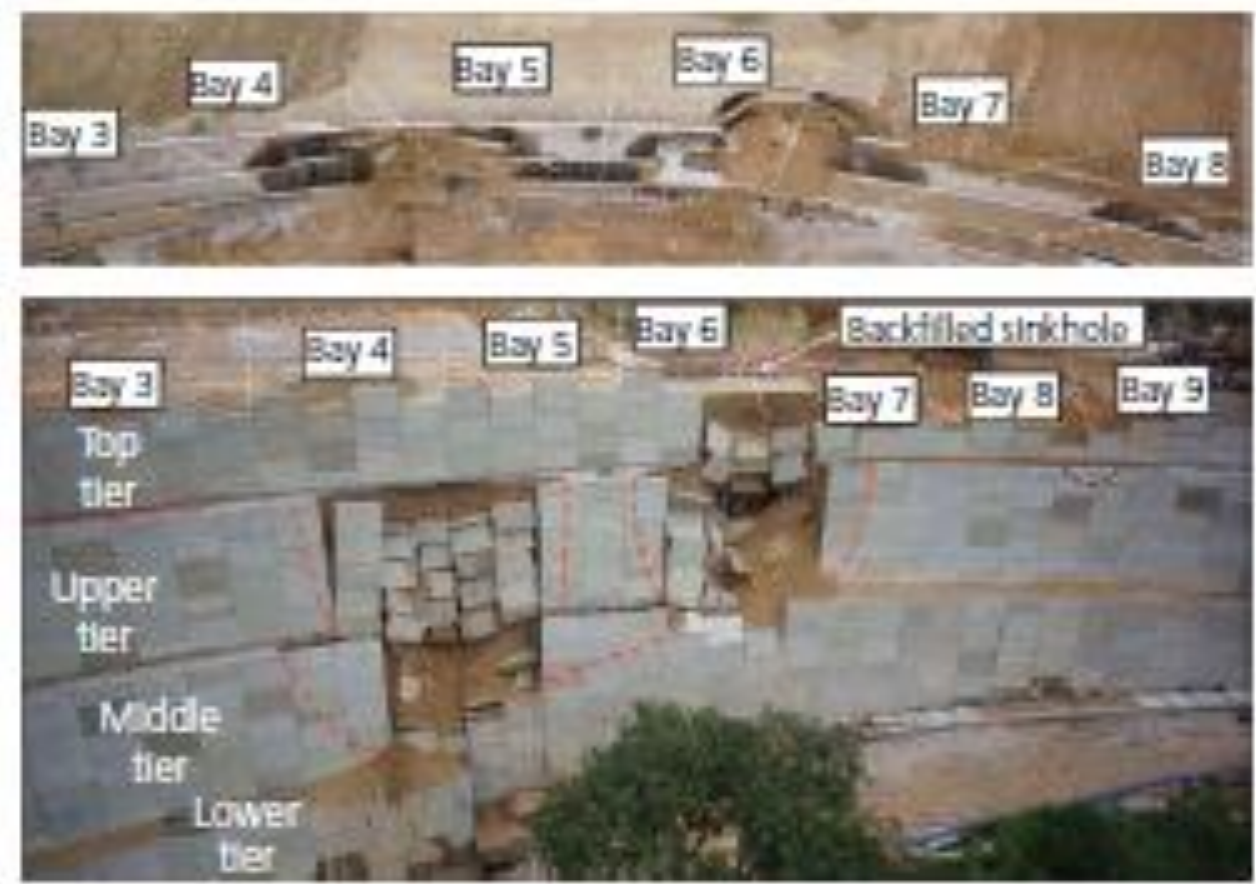

Figure 7. Aerial views of the 22 May 2013 incident at Wall R22 


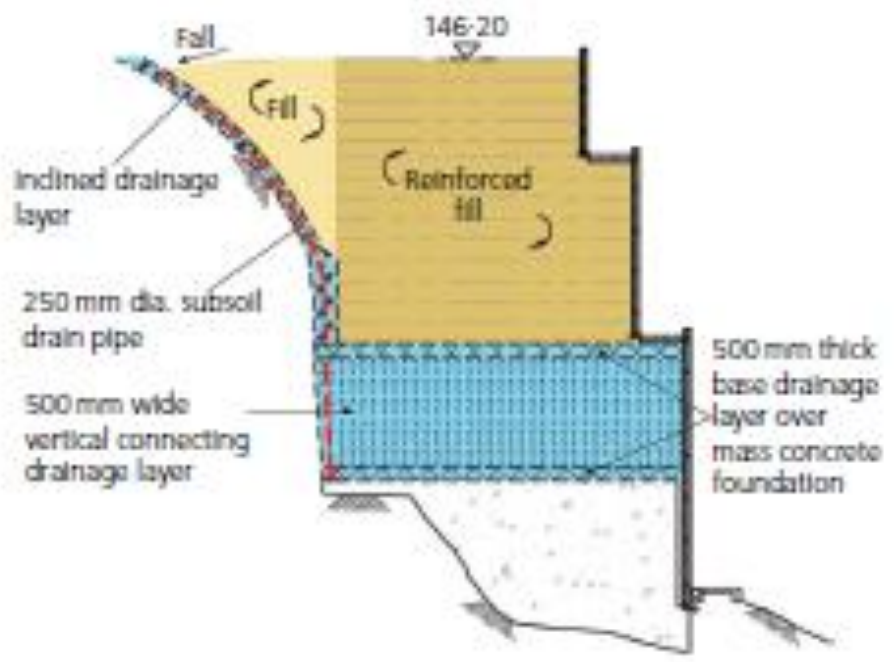

524

(a)

525

526

527

528

529

530

531

532

533

534

535

536

537

538

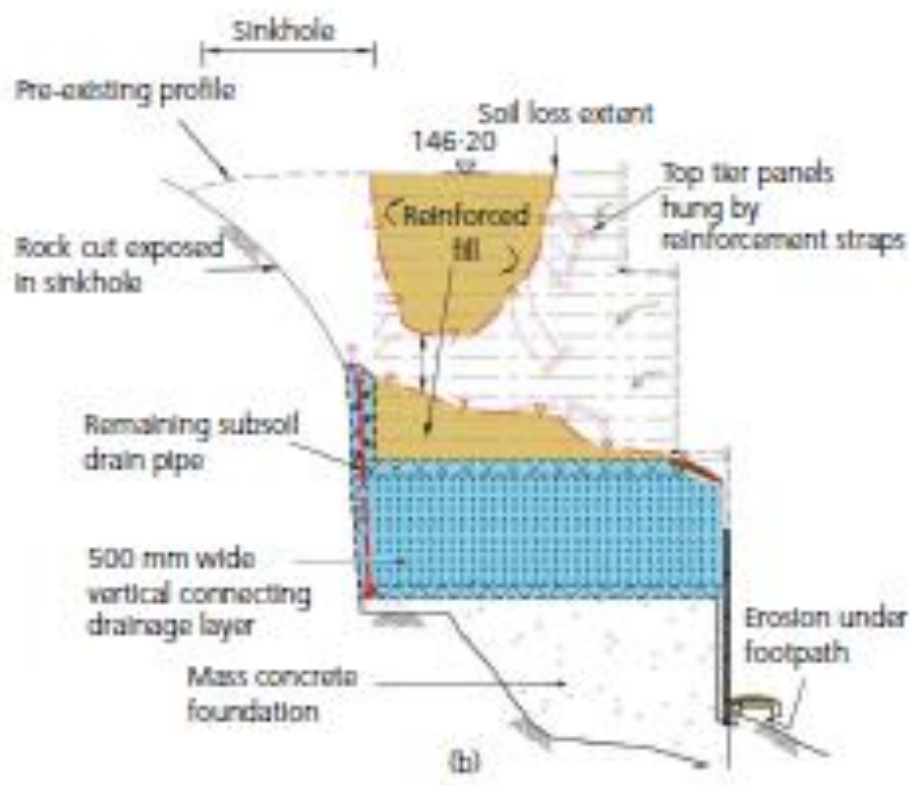

539

540

541 Figure 8. Pre- and post-incident cross-sections of Wall R22 at the interface between Bays 6 and 5427

543 
544

545

546

547

548

549

550

551

552

553

554

555

556

557

558

559

560

561

562

563

564

565

566

567

568

569

570

571

572

573

574

575

576

577

578

579

580 Figure 9. Backyard of Wall R22 on 21 May 2013
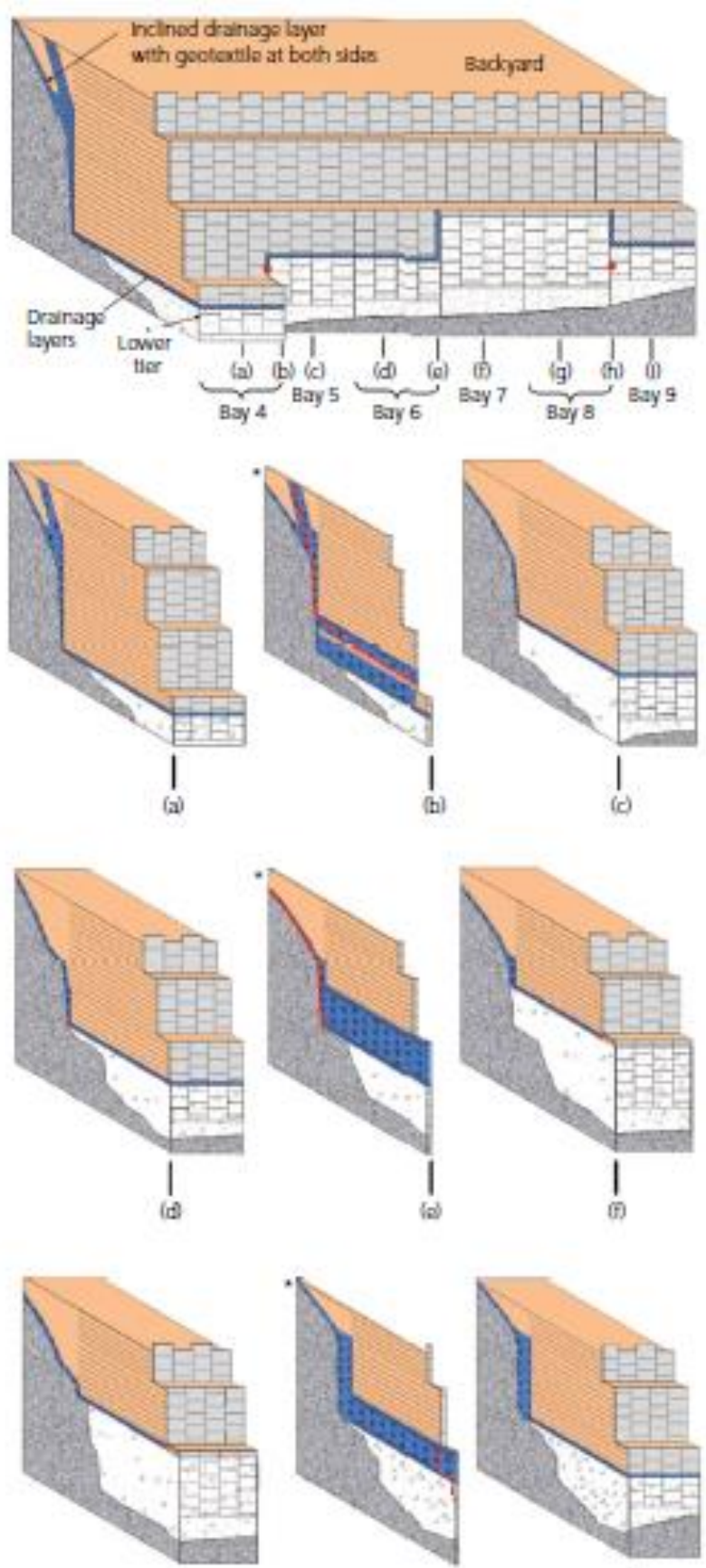

$$
\text { l }
$$

\rfloor$_{(1)}$

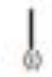

- Soctions cut along wortical connecting drainago loyer

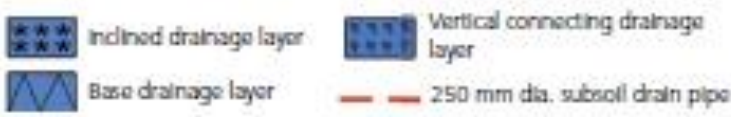

N/ Base drainage laycr

- $250 \mathrm{~mm}$ da. subsoli drain plpe 


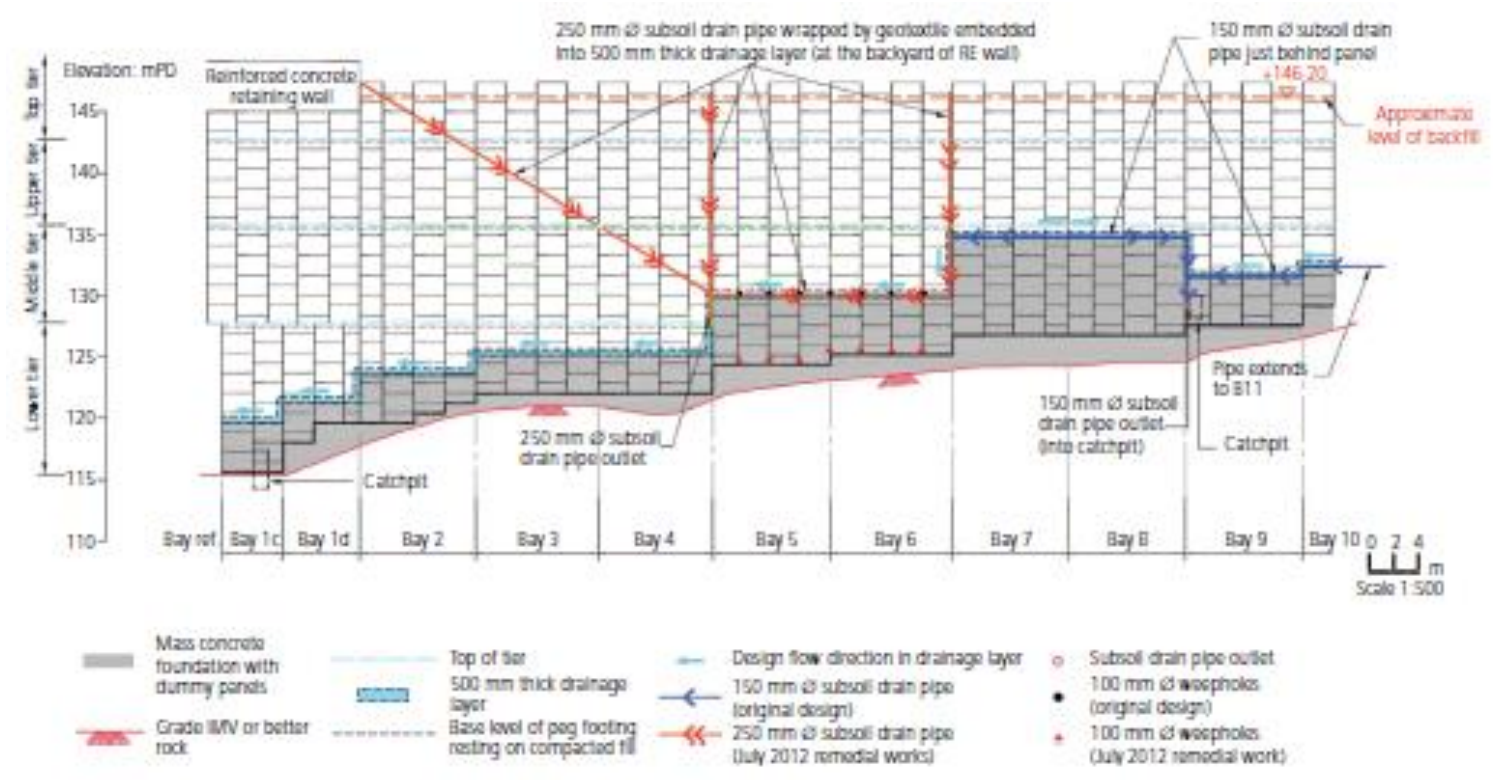

582

583

584 Figure 10. 3D spatial arrangement of the drainage layers and tiers

585

586

587

588

589

590

591

592

593

594

595

596

597

598

599

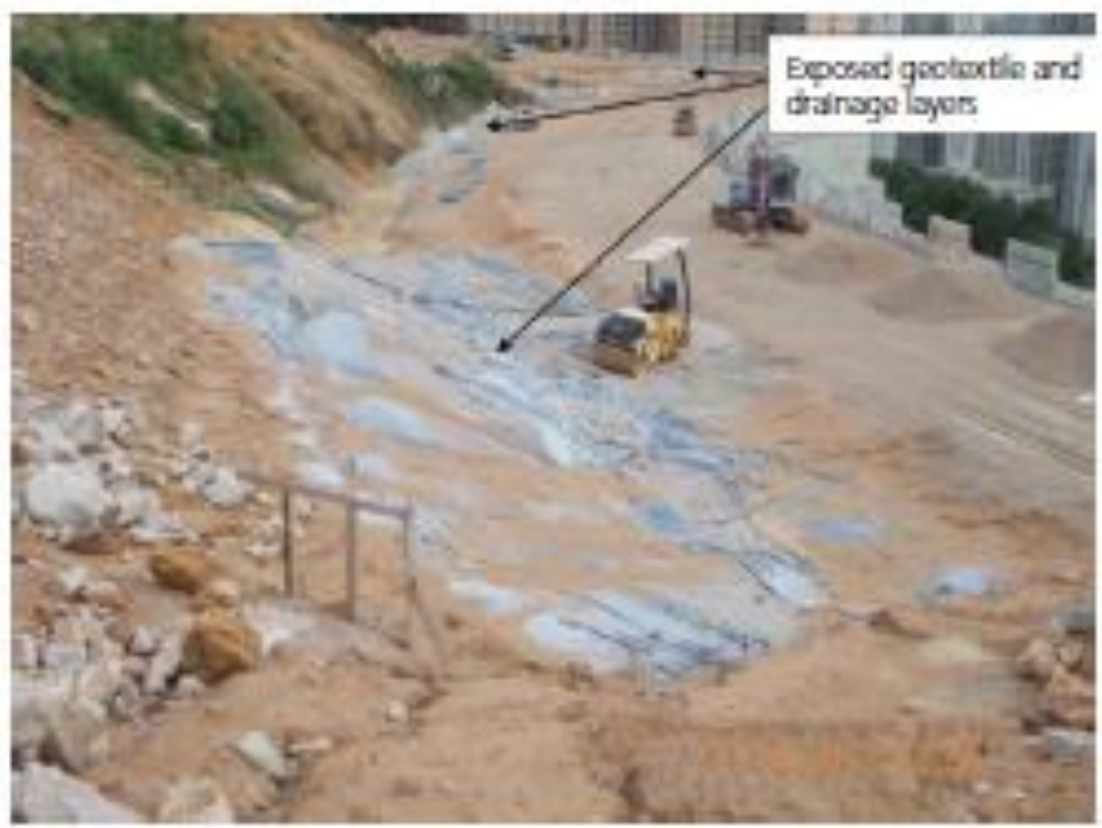

600

601

602

603

Figure 11. View of July 2012 incident at Bay 4/5

604 


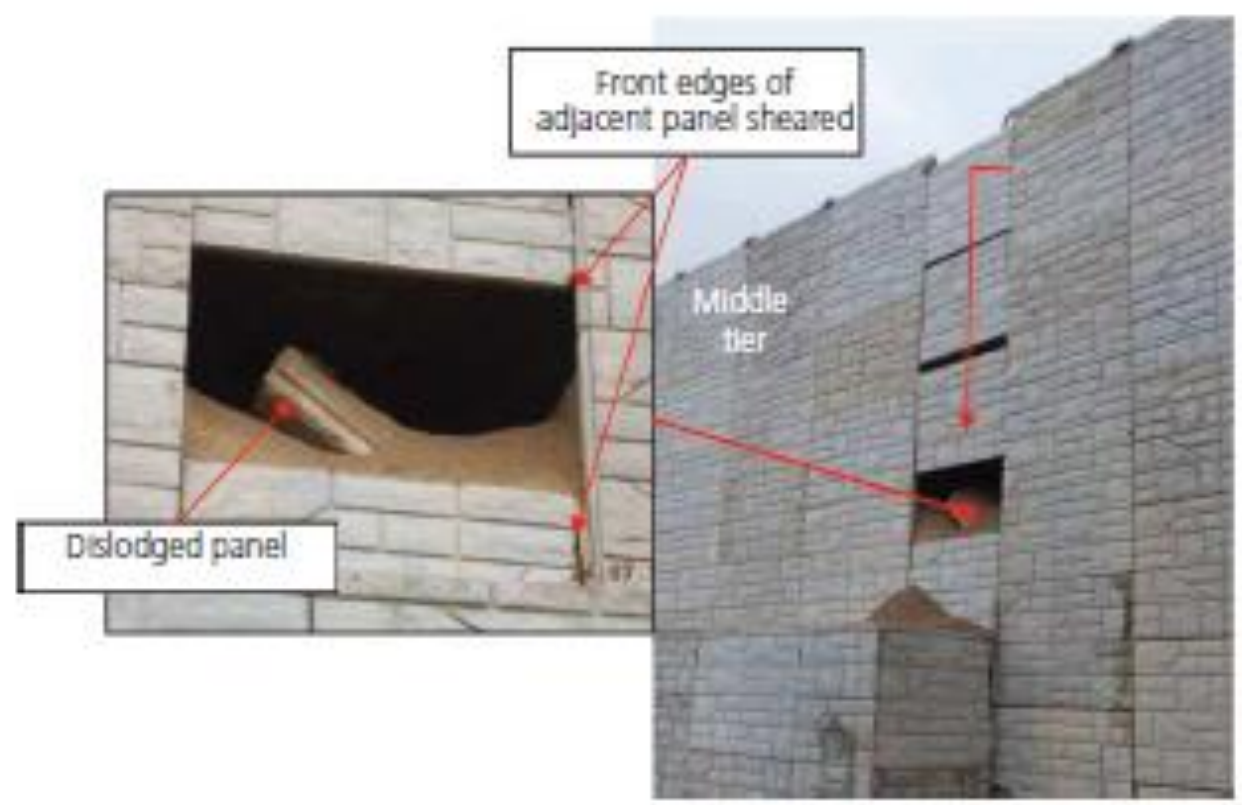

605

606

607 Figure 12. Sequence of distress at Bays $4 / 5$ of Wall R22

608 